\title{
An Experimental Observation: Countertops and Fire Ignition
}

\author{
Amber Mahan Ph.D. \\ Assistant Professor \\ Peru State College \\ Peru, Nebraska 68421 \\ United States \\ Samantha Carlson \\ Student \\ Peru State College \\ Peru, Nebraska 68421 \\ United States \\ Christian Callahan \\ Student \\ Peru State College \\ Peru, Nebraska 68421 \\ United States
}

\begin{abstract}
This observation was conducted in order to review fire ignition times and temperatures of four different mediums of countertops. The purpose was to review the mediums and fire ignition patterns to suggest a medium for homes as correlated to kitchen related fires. In 2016, there were approximately 1,342,000 fires reported in the United States (Fires in the U.S, n.d.). As a result of these fires, 3,390 were fatalities, 14,650 civilian injuries, and \$10.6 billion in property damage (Fires in the U.S, n.d.). One structure fire was reported approximately every 90 seconds. Unattended cooking is the leading factor in accidental home fires. Due to limitations, the significance of medium suggested, is minimum. The findings support use of man-made quarts or organic marble for homes allowing additional time to extinguish the fire or remove all parties to safety, while also allowing additional time for first responders. Further research in the area of forensic fire investigations and countertops is warranted to formulize the findings.
\end{abstract}

Keywords: Fire, Fire Ignition, Fire Hazards, Kitchen Fires, Countertops

\section{Introduction}

In 2016, there were approximately 1,342,000 fires reported in the United States (Fires in the U.S, n.d.). As a result of these fires, 3,390 were fatalities, 14,650 civilian injuries, and $\$ 10.6$ billion in property damage (Fires in the U.S, n.d.). One structure fire was reported approximately every 90 seconds. Unattended cooking is the leading factor in accidental home fires. Two-thirds of home cooking fires start when food or other cooking materials caught fire. In less than 30 seconds, a small flame can turn into a major fire. It only takes minutes for the thick black smoke to fill a house or for it to be engulfed in flames (Home Fires, n.d.).According to the U.S Fire Administration, every two and a half hours 'structure fires are fatal. From 2007 to 2011, over 156,000 fires were reported because of cooking oil or grease, a Class $\mathrm{K}$ fire (Fires Caused by month, n.d.). In this study, the researcher observed four different countertops to determine the time lapse for ignition and self-sustainability, as well as the temperature at ignition, if any. In determining the temperature and ignition rate for each respective countertop found in an average kitchen, the researchers can hypothetically determine which medium would slow down the fire process. Making suggestions on mediums of countertops may allow for additional time for residents to remove themselves from a fire emergency or allow extra time for the resident to put out the fire before spreading to other areas of the kitchen. This can potentially be attributed to the type of countertop that does not ignite or takes longer to ignite. Lastly, determining which countertop would allow for residence more time to survive the fire will in turn offer more time for arrival of first responders.

\section{A Brief Literature Review}

\subsection{Fire}


According to the National Fire Protection Association (NFPA) (2016), fire is described as "a rapid oxidation process, which is a chemical reaction resulting in the evolution of light and heat in varying intensities". Fire requires fuel, oxidizing agent, heat, and a chemical reaction (NFPA, 2016). To understand the triad of fire requirements, an understanding on development should be considered. Fire development is dependent upon fuel, ventilation, size and volume of fire location (room size), and temperature (ambient conditions) (NFPA, 2016).

\subsection{Kitchen: Fire Hazards}

As reported by NFPA (Ahrens, 2017), between the year 2011 - 2015, cooktops (with and without ovens), accounted for 62 percent of accidental cooking fires and 87 percent of deaths.

Additionally, unattended cooking fires remain the leading cause of fires result the reported deaths (Ahrens, 2017). During the same time frame, fire departments around the United States responded to approximately 170,200 fires involving cooking equipment per year. Thus resulting in an average of 466 home cooking fires daily (Ahrens, 2017). Approximately, 47 percent of those reported calls were structure fires listed as accidental caused by cooking incidents (Ahrens, 2017). Twenty-two percent of the 87 percent listed deaths, resulted from heat source (range) being too close to combustibles, such as linens, potholders, clothing, etc. that can easily catch fire unattended (Ahrens, 2017). Grease fires occur often in kitchens as a result of oil burning at an increased temperature or using disproportionate amount. If you increase the volume of oil required, oil can easily splash out of the pan onto the stove top (heat source). If applying to the triad, this situation now contains fuel (oil), heat source (stove top), and oxygen (especially if open concept) leading to a chemical reaction and fire. As stated by NFPA (Ahrens, 2017), between 2011 - 2015, "63 percent of the civilian deaths and 78 percent of civilian injuries, and direct property damage ( 76 percent) associated with cooking material or food ignitions resulted from these fat, grease or cooking oil fires" (p. vii). Additionally, a total of 66 percent of structure fires involving cooking equipment (range) started with ignition of cooking materials to include food (Ahrens, 2017).

\subsection{Temperature of Ignition}

According to the U.S. Department of Agriculture, studies on wood ignition conclude there is not a fixed temperature for ignition (Ragland, Aerts, \& Baker, 1991). Therefore, the moment of ignition depends on the amount of exposure time, the density of the wood, and type of wood. Cafe (2017) determined wood chars between $120-150$ degrees Celsius and various wood types ignite between 190 - 260 degrees Celsius taking approximately 14 minutes to be selfsustaining.

- Polyurethane most commonly used throughout the industry as a sealer for granite and also being used to impregnate HPS paper (laminate) is common to find in the modern home (Cafe, 2017). Polyurethanes have a melting point of 107 degrees Celsius to 137 degrees Celsius and an ignition temperature of 349 degrees Celsius. This is what began to burn before our materials or acted as an accelerant in the observation (Cafe, 2017).

- Sealed granite or a piece of laminated countertop with a polyurethane is more likely to spread fire across the surface, as shown from the presence of spalding noted in the observation.

- Quartz, an engineered stone, is approximately 90 percent organic materials and ten percent epoxies or resins (Cafe, 2017). Frequently the ten percent is polyester resins.

- Polyesters have a melting point of 220 - 268 degrees Celsius and ignition temperatures 432 - 488 degrees Celsius (Cafe, 2017). This could be the reason in unverified sources, quartz has burned. During the observation, due to the listed limitations, the quartz sample did not ignite.

\subsection{Prevention}

The action of stopping something from happening or arising is called prevention and a state of readiness is called preparedness (Preparedness, n.d.). When cooking, it is recommended to stay in the kitchen during that time. Food can easily boil over or grease can spatter over the pan and land on a rag to catch on fire. Other techniques people can be aware of is to keep cooking surfaces and countertops cleared off so certain items cannot catch on fire. Items that are commonly on countertops easily catch on fire; are pot holders, towels, curtains, bags, and other appliances. A method of preparedness is to know what to do when a fire occurs. If a fire starts while cooking with a pan that has a lot of grease or oil in it, then it is suggested to glide a lid over the burning pan and turn the burner off. When the pan is completely cooled off then remove the lid. It is recommended not move the pan due to the possibility of personal injury or spreading fire. The golden rule when dealing with kitchen grease fire is to never pour water on to the fire. Before leaving the kitchen you should always check to see if the stove, oven, and other small appliances are turned off.

\subsection{First Responder Response Times}


According to Flynn (2009), the difference between fire department response times vary based on the several variables to include; demographics, zoned area (urban, rural, suburban, remote, and special risks), populations, paid department verses volunteer department, etc. NFPA 1720 recommends the following (Flynn, 2009):

- Urban area (>1000 people per square mile) 9-minute response time

- Suburban area (500-100 people per square mile) 10-minute response time

- Rural area (>500 people per square mile) 14-minute response time

- Remote area dependent of travel distance from fire station

Each of the above recommendations also depends on number of staff, if staff is volunteer requiring commuter time, hours of the day, etc. to be successful in fire suppression and preservation of life.

NFPA 1710 recommends fire departments leave the fire station upon a call for service within 80 seconds and arrive on scene in four minutes or less without taking into consideration fire suppression time (Flynn, 2009). Realistically, this is a 6-minute average response time (Flynn, 2009).

\section{The Site \& Methods}

To replicate a structure fire using countertops, the researchers used a Southeast Nebraska closed fire department bay. The average temperature recorded for the facility at the time of the observation was 66 degrees Fahrenheit without ventilation. The researchers utilized four types of countertop to include; butcher block, laminate, granite, and quartz. The size of each countertop varied, as all were donated. Each of the four countertops were photographed before and after. Time lapse was taken during and stopped when the countertop had ignited and was self-sustaining. If failed to ignite, the clock stopped at 1:00:00 minute. Temperature was taken by way of Bullard T4 Max thermal imager at the moment the countertop ignited or failed to ignite. The researchers utilized a blow torch, UL100, rated to reach 3400 degrees Fahrenheit/1871 degrees Celsius, as a method of ignition for each countertop.

\section{Results \& Discussion}

\begin{tabular}{|l|l|l|}
\hline Type of Countertop & Ignition Temperature (Celsius) & Time Lapse \\
\hline Laminate & $224^{\circ}$ & $20.94 \mathrm{Sec}$ \\
\hline Butcher Block & $396^{\circ}$ & $1: 02: 00$ \\
\hline Quartz & N/A & $1: 00: 00$ \\
\hline Granite & N/A (Spaulding only) & $1: 00: 00$ \\
\hline
\end{tabular}

During the observation, the laminate countertop ignited at 224degreesCelsius self-sustaining at 20.94 seconds. Butcher block ignited at 396degreesCelsius self-sustaining at 1:02:00. After one minute, quartz failed to ignite and the highest temperature recorded on the surface was 292 degrees Celsius. The granite failed to ignite after one minute and rose to a surface temperature of 181 degrees Celsius. Although, granite failed to ignite in one minute's time, at 52 seconds, spaulding was apparent at the surface level only. A statistical analysis was not computed due to a low effect size and increased limitations with temperature and medium.

\section{Limitations}

In regards to this research, several limitations plagued the expected outcome, however being a simple observation, this was expected. The countertop materials, although common mediums of countertops, were donated for this research project. The size of each varied and any sealants/resin applied to the countertop remains unknown. Therefore, selfsustaining fire ignition may have been a result of the sealant and not the medium of the countertop. To simulate a structure fire (house), the fire bay was closed during the research which cut off oxygen flow to the ignition source, therefore may have lessened the ability for the countertop to remain self-sustaining, more oxygen equates to more fire. Heat is the "component necessary to increase the temperature of the fuel in the present oxygen and cause ignition" (Redsicker, 2005). Several contributors participated during the research observation, a fire fighter ignited each countertop one by one, while another used the thermal imager, while a student operated the time clock and second thermal imager, and second student recorded the results of both ignition time and temperature. Therefore, the likelihood of being off by a second/degree per each countertop is grave. Lastly, quartz is a form of engineered stone (man-made), whereas granite is organic (mined). Although, quartz will ignite, for this observational experiment, the conditions were not hot enough for ignition. Further, due to lack of research and reported fire ratings per each countertop medium, the true ignition time and temperature is unknown.

\section{Discussion \&Conclusion}

Due to the facility utilized for this research, there was difficulty obtaining a certain read on the temperature of ignition. The facility had little ventilation to help ignite the fire, as it was an enclosed area with little air flow. The researchers 
used a UL100 blow torch to set the countertops on fire. As the torch was rated to reach 3400 degrees Fahrenheit/1871 degrees Celsius, it was unable to reach that point at the time of the research. Made from one of the hardest minerals on earth, quartz countertops are arguably the most durable option for kitchens. Quartz countertops (man-made) are made up of 94 percent quartz itself and then the other six percent is resins, which appears to be the material that catches on fire, solely based on this research. The lack of research about countertops catching fire, makes it difficult to support these findings, as there were many limitations negatively impacting the outcome. Granite is a stone that can last a lifetime (organic). A countertop that is made out of granite can hold up to extreme temperature but similar to quartz, it is difficult to support the findings because of the lack of research that has been done with countertops themselves. Observations from this research, would suggest modern homes built using granite or quartz countertops may have a longer ignition period over laminate and butch block. Therefore, allowing residents a longer period to remove themselves from the fire, put the fire out before spreading, or allow more time for fire departments to arrive. If the national response time is recommended to be 6 minutes or less and laminate ignites in approximately 20.94 seconds, the fire has increased in size over the course of 5.65 minutes prior to the fire department arrival.

\section{References}

Ahrens, M. (2017). Home fires involving cooking equipment. National Fire Protection

Association. Retrieved from https://www.nfpa.org/-/media/Files/News-and-Research/Fire-statistics/MajorCauses/oscooking.pdf

Cafe, T. (2017). Physical constants for investigators. T.C. Forensic. Retrieved from http://www.tcforensic.com.au/docs/article10.html

Fire Causes by month. (n.d.). Retrieved https://www.nfpa.org/-/media/Files/News-and-Research/Fire-statistics/Factsheets/FireCausesByMonth

Fires in the US (n.d.). Retrieved from https://www.nfpa.org/News-and-Research/Fire-statistics-and-reports/Firestatistics/Fires-in-the-US

Flynn, J. D. (2009). Fire service performance measures. National Fire Protection Association. Retrieved from https://www.nfpa.org/-/media/Files/News-and-Research/Firestatistics/Fireservice/osfsperformancemeasures.ashx?la=en

Home Fire Preparedness. (n.d.). Retrieved from http://www.redcross.org/get-help/how-toprepare-for-emergencies/types-of-emergencies/fire/home-fire-preparedness

NFPA. (2016). Fire dynamics. National Institute of Standards and Technology. Retrieved from https://www.nist.gov/\%3Cfront\%3E/fire-dynamics

Preparedness. (n.d.). Retrieved from https://www.merriam-webster.com/dictionary/preparedness

Prevention Synonyms, Prevention Antonyms. (n.d.). Retrieved from https://www.merriam-webster.com/thesaurus/prevention

Ragland, K. W., Aerts, D. J., \& Baker, A. J. (1991). Properties of wood for combustion analysis. Bioresource Technology, 37(2), 161-168.

Redsicker, D. R. (2005). Basic fire and explosion investigation. In S. H. James \& J. J. Nordby (2 $\left.{ }^{\text {nd. }}\right)$, Forensic science: An introduction to scientific and investigative techniques (pp. 489-507). Boca Raton, FL: Taylor \& Francis. 